Int. J. Electrochem. Sci., 15 (2020) $7119-7135$

\title{
Characterization and Preparation of Metallic Nanoparticles Decorated Graphene Oxide/ Carbon Nanotube on Polytetrafluoroethylene Membrane as an electrochemical Filter for Wastewater Treatment
}

\author{
Xianliang $\mathrm{Li}^{1^{*}}$, Tao Xia ${ }^{2}$ \\ ${ }^{1}$ College of Bioengineering, Jingchu University of Science and Technology, Jingmen 448000, China \\ ${ }^{2}$ School of life sciences, Huazhong Agricultural University, Wuhan 430071, China \\ *E-mail: lixianling163@ sina.com
}

doi: $10.20964 / 2020.08 .60$

Received: 30 March 2020 / Accepted: 19 May 2020 / Published: 10 July 2020

\begin{abstract}
Nowadays, the increasing demand and the reduction of sources of drinking water are the big challenges for all industries. Therefore, studying and designing a high efficiency wastewater treatment device is essential. In this work, graphene oxide (GOx), Au nanoparticles decorated graphene oxide (AuGOx) and Ag nanoparticles decorated graphene oxide (AgGOx) electrode was applied to electrooxidation of tetracycline, phenol and oxalate from both of deionized and real water samples. The GOx, AuGOx and AgGOx structures were synthesized through chemical approach. The structural properties of synthesized GOx, AuGOx and AgGOx were studied by FESEM and XRD. Results showed that the prepared structures had high density, aspect ratio and porosity. Electrochemical properties of filters were investigated by differential pulse voltammetry (DPV), electrochemical impedance spectroscopy and chronoampermetry techniques. The result showed that AgGOx/CNTs filter exhibited higher electro-oxidation rate than GOx, AuGOx filters. The DPV findings indicated that AgGOx/CNTs can be the proposed filter to remove phenol from real wastewater samples.
\end{abstract}

Keywords: Metallic nanoparticles; Graphene oxide electrode; Wastewater treatment; Differential pulse voltammetry

\section{$\underline{\text { FULL TEXT }}$}

(C) 2020 The Authors. Published by ESG (www.electrochemsci.org). This article is an open access article distributed under the terms and conditions of the Creative Commons Attribution license (http://creativecommons.org/licenses/by/4.0/). 